\title{
Prevalência de erros em imagens de radiografia panorâmica entre profissionais mais e menos experientes
}

\section{Fernanda P. Murad ${ }^{\star}$, Wilson G. Cral, Eliana D. da Costa, Glaucia M. B. Ambrosano, Deborah Q. de Freitas.}

\section{Resumo}

O objetivo nesse estudo foi avaliar a prevalência de erros na execução da técnica da radiografia panorâmica entre mestrandos e doutorandos em Radiologia Odontológica. A amostra consistiu em 771 imagens de radiografias panorâmicas, as quais foram classificadas de acordo com o grupo de pacientes (crianças, adultos, desdentados totais e parciais) e com o profissional que executou a técnica (mestrandos e doutorandos). Dois avaliadores verificaram a presença/ausência de erros nas imagens, bem como a repetição das imagens com erros. Análise descritiva foi realizada para verificar a frequência de erros, e o teste qui-quadrado para analisar os erros das radiografias panorâmicas em relação ao grupo de pacientes e formação do profissional. Os resultados mostraram que a frequência de exames corretos foi inferior a $50 \%$ para ambos os profissionais para todos os grupos de pacientes. Mestrandos não realizaram uma nova aquisição diante de radiografias com erros em $41,7 \%$ dos exames realizados em crianças, $52,4 \%$ dos exames de adultos e $58,8 \%$ dos exames de pacientes desdentados parciais. Já para os doutorandos, a frequência de não realização de um novo exame diante de um erro foi menor em adultos $(43,0 \%)$, seguido por crianças $(48,4 \%)$, desdentados parciais $(53,0 \%)$ e desdentados totais $(57,1 \%)$. Não houve associação significativa da porcentagem de exames com erros e da porcentagem de repetição com a formação do profissional e grupo de pacientes $(p<0,05)$. Conclui-se que treinamentos com relação a técnica radiográfica panorâmica são necessários independente da formação do profissional.

\section{Palavras-chave:}

Radiografia Panorâmica, Radiologia, Diagnóstico.

\section{Introdução}

A radiografia panorâmica é uma técnica radiográfica bastante sensível a erros, pois depende da colaboração do paciente e da habilidade do operador em realizá-la.

Nesse sentido, para garantir a qualidade da imagem radiográfica, é de extrema importância a supervisão do pessoal especializado e cuidados na execução da técnica. Imprecisões no posicionamento do paciente podem causar discrepâncias e consequentemente causam distorção da imagem, comprometendo 0 valor diagnóstico da radiografia panorâmica.

Clinicamente, a obtenção de uma radiografia panorâmica de qualidade é necessária para evitar repetição do exame e, consequentemente, minimizar a exposição desnecessária do paciente à radiação.

O objetivo nesse estudo foi avaliar a prevalência de erros na execução da técnica da radiografia panorâmica entre mestrandos e doutorandos em Radiologia Odontológica.

\section{Resultados e Discussão}

O estudo foi aprovado pelo Comitê de Ética em Pesquisa da Faculdade de Odontologia de Piracicaba UNICAMP, pelo CAAE n 93632518.4.0000.5418.

A amostra consistiu em 771 imagens de radiografias panorâmicas, as quais foram classificadas de acordo com o grupo de pacientes (crianças, adultos, desdentados totais e parciais) e com o profissional que executou a técnica (mestrandos e doutorandos). Dois avaliadores verificaram a presença/ausência de erros nas imagens, bem como a repetição das imagens com erros. Análise descritiva foi realizada para verificar a frequência de erros, e o teste qui-quadrado para analisar os erros das radiografias panorâmicas em relação ao grupo de pacientes e formação do profissional.

Os resultados mostraram que a frequência de exames corretos foi inferior a $50 \%$ para ambos os profissionais para todos os grupos de pacientes.

Mestrandos não realizaram uma nova aquisição diante de radiografias com erros em $41,7 \%$ dos exames realizados em crianças, $52,4 \%$ dos exames de adultos e $58,8 \%$ dos exames de pacientes desdentados parciais.

Para os doutorandos, a frequência de não realização de um novo exame diante de um erro foi menor em adultos (43,0\%), seguido por crianças $(48,4 \%)$, desdentados parciais $(53,0 \%)$ e desdentados totais $(57,1 \%)$. Não houve associação significativa da porcentagem de exames com erros e da porcentagem de repetição com a formação do profissional e grupo de pacientes $(p<0,05)$.

\section{Conclusões}

Conclui-se que treinamentos com relação a técnica radiográfica panorâmica são necessários independente da formação do profissional.

\section{Agradecimentos}

\section{À UNICAMP, PRP, CNPq.}

\footnotetext{
${ }^{1}$ Mohtavipour ST et al. Common errors in digital panoramic radiographs taken in rasht dental school. J Of Dent Radiol, Pathol and Surgery. 2013; 2(2): 33-6

${ }^{2}$ Khator AM, Motwani MB, Choudhary AB. A study for determination of various positioning erros in digital panoramic radiography for evaluation of diagnostic image quality. Indian J Dent. 2017; 28(6): 666-70.
} 